OPEN ACCESS

Edited by:

Qiang Wei,

Sichuan University, China

Reviewed by:

Min Bao,

California Institute of Technology,

United States

Lindsey Westover,

University of Alberta, Canada

*Correspondence:

Melanie Haffner-Luntzer

melanie.haffner-luntzer@uni-ulm.de

Specialty section:

This article was submitted to

Biomaterials,

a section of the journal

Frontiers in Bioengineering and

Biotechnology

Received: 15 August 2020

Accepted: 25 September 2020

Published: 21 October 2020

Citation:

Steppe L, Liedert A, Ignatius A and Haffner-Luntzer M (2020)

Influence of Low-Magnitude High-Frequency Vibration on Bone

Cells and Bone Regeneration.

Front. Bioeng. Biotechnol. 8:595139.

doi: 10.3389/fbioe.2020.595139

\section{Influence of Low-Magnitude High-Frequency Vibration on Bone Cells and Bone Regeneration}

\author{
Lena Steppe, Astrid Liedert, Anita Ignatius and Melanie Haffner-Luntzer* \\ Institute of Orthopedic Research and Biomechanics, UIm University Medical Center, Ulm, Germany
}

Bone is a mechanosensitive tissue for which mechanical stimuli are crucial in maintaining its structure and function. Bone cells react to their biomechanical environment by activating molecular signaling pathways, which regulate their proliferation, differentiation, and matrix production. Bone implants influence the mechanical conditions in the adjacent bone tissue. Optimizing their mechanical properties can support bone regeneration. Furthermore, external biomechanical stimulation can be applied to improve implant osseointegration and accelerate bone regeneration. One promising anabolic therapy is vertical whole-body low-magnitude high-frequency vibration (LMHFV). This form of vibration is currently extensively investigated to serve as an easyto-apply, cost-effective, and efficient treatment for bone disorders and regeneration. This review aims to provide an overview of LMHFV effects on bone cells in vitro and on implant integration and bone fracture healing in vivo. In particular, we review the current knowledge on cellular signaling pathways which are influenced by LMHFV within bone tissue. Most of the in vitro experiments showed that LMHFV is able to enhance mesenchymal stem cell (MSC) and osteoblast proliferation. Furthermore, osteogenic differentiation of MSCs and osteoblasts was shown to be accelerated by LMHFV, whereas osteoclastogenic differentiation was inhibited. Furthermore, LMHFV increased bone regeneration during osteoporotic fracture healing and osseointegration of orthopedic implants. Important mechanosensitive pathways mediating the effects of LMHFV might be the Wnt/beta-catenin signaling pathway, the estrogen receptor (ER) signaling pathway, and cytoskeletal remodeling.

Keywords: bone, fracture healing, vibration, LMHFV, osseointegration, mechanostimulation, regeneration

\footnotetext{
Abbreviations: Akt, protein kinase B; ALP, alkaline phosphatase; BF, peri-implant bone formation; BIC, bone-toimplant contact; BMP, bone morphogenetic protein; BMSCs, bone marrow-derived MSCs; Col-1, collagen type I; Cox2, cyclooxygenase 2; ER, estrogen receptor; ERK1/2, extracellular signal-regulated kinase 1/2; g, gravitational acceleration; GJIC, gap junctional intracellular communication; Hz, hertz; IL, interleukin; LMHFV, low-magnitude high-frequency vibration; Lrp6, low-density lipoprotein receptor-related protein 5; MMP, matrix metallopeptidase; MSCs, mesenchymal stem cells; OCN, osteocalcin; OPG, osteoprotegerin; OPN, osteopontin; OVX, ovariectomy; PTH, parathyroid hormone; RANKL, receptor activator of nuclear factor-kappa B ligand; siRNA, small interfering RNA; SOST, sclerostin; TGF- $\beta$, transforming growth factor beta; TNF- $\alpha$, tumor necrosis factor alpha; TRAP, tartrate resistant acid phosphatase.
} 


\section{INTRODUCTION}

Bone is a mechanosensitive tissue which can react to changing loads by adapting bone mass and structure. Osteocytes are considered to be the main mechanosensor cell type in bone (Lanyon, 1993). However, other bone cells, including osteochondroprogenitor cells and osteoblasts, were also shown to react to their biomechanical environment by activating molecular signaling pathways, which regulate their proliferation, differentiation, and matrix production. Additionally, bone fracture healing critically depends on the mechanical conditions in the fracture area. Rigid fixation of long-bone fractures resulting in small interfragmentary movements induce direct intramembranous bone healing, whereas flexible fixation with higher interfragmentary movements results in callus healing with endochondral bone formation (Perren, 1979). Too flexible fixation can cause non-unions with hypertrophic fibrous tissue near the fracture gap. Similarly, too low biomechanical stimulation could be negative for bone healing. Regarding the underlying mechanism, it is proposed that mesenchymal cells are likely to form fibrous tissue under high stress conditions, whereas osseous tissue is generated under low stress conditions. At intermediate stresses, mesenchymal cells will differentiate into chondrocytes and initiate cartilaginous callus formation, which initially bridges the fracture gap (Claes et al., 2011). Therefore, the biomechanical environment appears to crucially influence bone cells during homeostasis, remodeling, and regeneration. Furthermore, the biomechanical environment plays a critical role during osseous implant integration. The implant material, its surface characteristics, and its biomechanical properties are major factors which should positively influence recruitment and differentiation of osteogenic cells to the implant surface to avoid implant loosening. Therefore, the development of new orthopedic implant materials and coatings is of great interest. Furthermore, because of the mechanosensitivity of bone, the application of external biophysical stimulation, including LMHFV, is considered to promote bone formation. This approach offers many benefits as a safe, easy-to-apply, and an effective treatment option which might be useful not only for preventing the risk of fractures but also for improving bone regeneration and implant osseointegration. Preclinical and clinical studies have already reported that vertical whole-body LMHFV is a successful anabolic strategy for healthy and osteoporotic patients to increase bone mineral density (Dubosc-Marchenay et al., 1992; Rubin et al., 2004; Ward et al., 2004; Xie et al., 2006; Wenger et al., 2010; Tezval et al., 2011). However, the underlying molecular pathways remain largely unknown. To shed some light on mechanotransduction pathways of LMHFV and the involved bone cells, in vitro studies with the focus on osteoblasts, osteoclasts, or their progenitors are reviewed. In addition, studies applying LMHFV during fracture healing or implant integration are discussed in this review article.

\section{MATERIALS AND METHODS}

The study was conducted in accordance with the PRISMA guidelines for systematic reviews. The electronic databases PubMed and Web of Science were reviewed regarding (1) influence of LMHFV on bone cells in vitro and the involved signaling pathways and (2) influence of LMHFV on bone regeneration in vivo (implant integration and fracture healing). The search strategies were focused on the PICOS criteria, which establish the inclusion and exclusion criteria as well as the combination of keywords for the studies to be analyzed. For search strategy (1), any controlled in vitro study, written in the English language was included. Studies including either mouse cell lines of osteoblasts (MC3T3-E1), osteoclasts (RAW264.7), or osteocytes (MLO-Y4) as well as MSCs or the respective primary cells derived from humans or rodents were considered. Only studies applying LMHFV $(<1 g, g ; 20-90 \mathrm{~Hz})$ in a vertical manner were selected; therefore, acoustical and ultrasound oscillations were excluded. The primary outcome measures were proliferative capacities of the respective investigated cell type as well as their differentiation and changes in gene or protein expression. For (2), any preclinical study involving any animal species written in the English language was included. The primary outcome measures were callus formation, vascularization, bone formation and remodeling, mechanical stability of newly formed bone, and immune cell responses during fracture healing. Full papers of the final list of studies were reviewed and study data extracted and summarized in tables for subsequent analysis and discussion. In total, 51 articles were included in this paper. Vertical LMHFV was applied by either custom-made or commercially available vibration platforms in the studies reviewed in this article.

\section{RESULTS}

\section{Influence of LMHFV on Bone Cells in vitro and the Involved Signaling Pathways MSCs}

Mesenchymal stem cells are multipotent stem cells with the capacity to differentiate into different lineages, that is, osteogenic, chondrogenic, adipogenic, and myogenic (Pittenger et al., 1999; Kolf et al., 2007; Rastegar et al., 2010). The fate of MSCs is profoundly influenced by biomechanical stimuli (Pauwels, 1960). It is of great interest for the development of regenerative strategies to investigate whether LMHFV can favor MSC differentiation toward one specific lineage and which molecular mechanisms are involved.

Experimental in vitro studies used BMSCs or adipose-derived MSCs isolated from human, rat, or mouse BMSCs as well as the murine bone marrow stem cell line D1-ORL-UVA. To elucidate the effects of vibration, the cells were subjected to a specific vibration regime; however, loading parameters and time schedules varied among the studies (Table 1), but were within the range of $20-90 \mathrm{~Hz}$ and $<1 \mathrm{~g}$ magnitude. It was demonstrated by the majority of studies, that LMHFV induced the expression 
TABLE 1 | LMHFV effects on mesenchymal stem cells.

\begin{tabular}{|c|c|c|c|c|c|c|}
\hline References & Cells & Environment & $\begin{array}{l}\text { Frequency } \\
\qquad(\mathrm{Hz})\end{array}$ & $\begin{array}{l}\text { Magnitude } \\
\qquad\left({ }^{*} g\right)\end{array}$ & Time schedule & Main outcome \\
\hline Baskan et al., 2017 & D1-ORL-UVA & TCP & 90 & 0.15 & $15 \mathrm{~min} /$ day 7 days & Adipogenic markers $\downarrow$ \\
\hline Chen et al., 2016 & rBMSCs & HA-coated titanium scaffolds (3D) & 40 & 0.3 & $30 \mathrm{~min} /$ day 14 days & Expression of osteogenic markers (Runx2, Osx, Col-1, OC) $\uparrow$ \\
\hline Demiray and Özçivici, 2015 & D1-ORL-UVA & TCP & 90 & 0.15 & $\begin{array}{l}15 \mathrm{~min} / \text { day for } \\
7 \text { days }\end{array}$ & $\begin{array}{l}\text { Cytoskeletal adaptations: } \\
\text { total actin content and actin fiber thickness } \uparrow \\
\text { Cell proliferation } \uparrow\end{array}$ \\
\hline Lau E. et al., 2011 & rMSCs & TCP & 60 & 0.3 & $\begin{array}{l}1 \mathrm{~h} / \text { day on days } \\
1+2 \text { and } 4-6\end{array}$ & Osteogenesis $\downarrow$ \\
\hline Li et al., 2019 & rBMSCs & TCP (not stated) & 45 & 0.9 & $30 \mathrm{~min} /$ day 5 days & Expression of osteogenic markers (Runx2, Osx, Col-1, OCN) $\uparrow$ \\
\hline Lu et al., 2018 & BMSCs & TCP (not stated) & 40 & 0.3 & $15 \mathrm{~min} /$ day & $\begin{array}{l}\text { Cell proliferation and mineralization } \uparrow \\
\text { Expression of osteogenic markers (Runx2, Col-I, ALP, OPN, OC) } \uparrow\end{array}$ \\
\hline Marycz et al., 2016 & hASCs & TCP & $25,35,45$ & 0.3 & $15 \mathrm{~min} /$ day 14 days & $\begin{array}{l}\text { Expression of osteogenic and chondrogenic markers (BMP-2, Col-II, } \\
\text { Sox9) } \uparrow \\
\text { Adipogenesis } \downarrow\end{array}$ \\
\hline Mehta, 2015 & hMSCs & Synthetic 3D scaffold (PEGDA) & 100 & $\begin{array}{l}0.3 \\
3 \\
6\end{array}$ & $24 \mathrm{~h}$ & Osteogenic differentiation (ALP) and mineralization $\uparrow$ \\
\hline Kim et al., 2012 & hMSCs & Collagen sponge (3D scaffold), TCP & $30-40$ & 0.3 & $\begin{array}{l}10 \mathrm{~min} / \text { day } \\
5 \text { days }\end{array}$ & $\begin{array}{l}\text { Expression of osteogenic and vascularization-related markers (Col-I, } \\
\text { OPG, VEGF, VEGF) } \uparrow\end{array}$ \\
\hline Pongkitwitoon et al., 2016 & hBMCs & TCP & 30 or 100 & $\begin{array}{c}0.15 \\
1\end{array}$ & $\begin{array}{l}2 \times 20 \mathrm{~min} / \text { day } \\
(2 \mathrm{~h} \text { rest period })\end{array}$ & $\begin{array}{l}\text { Cell proliferation } \uparrow \\
\text { Expression of osteogenic markers (Runx2, ALP) } \uparrow\end{array}$ \\
\hline Uzer et al., 2013 & hASCs & TCP & 30 or 100 & $\begin{array}{l}0.15 \\
1 \\
2\end{array}$ & $30 \mathrm{~min} / \mathrm{day}$ & $\begin{array}{l}\text { Cell proliferation and mineralization } \uparrow \\
\text { Cytoskeletal remodeling } \uparrow\end{array}$ \\
\hline Uzer et al., 2015 & mBMSCs & TCP or collagen-I coated plates & 90 & 0.7 & $2 \times 20 \mathrm{~min} /$ day & Cytoskeletal remodeling $\uparrow$ \\
\hline Zhou et al., 2011 & BMSCs & Human bone-derived scaffolds (3D) & 40 & 0.3 & $30 \mathrm{~min} / 12 \mathrm{~h}$ & $\begin{array}{l}\text { Expression of osteogenic markers (Col-I, OCN, ALP, Runx2) } \uparrow \\
\text { ERK1/2 pathway involved }\end{array}$ \\
\hline
\end{tabular}


TABLE 2 | LMHFV effects on osteoblasts.

\begin{tabular}{|c|c|c|c|c|c|}
\hline References & Cells & $\begin{array}{l}\text { Frequency } \\
(\mathbf{H z})\end{array}$ & $\begin{array}{l}\text { Magnitude } \\
\left.\qquad{ }^{\star} g\right)\end{array}$ & Time schedule & Main outcome \\
\hline García-López et al., 2020 & $\begin{array}{l}\text { Primary BALB/c mouse } \\
\text { calvarial osteoblasts }\end{array}$ & 30 & 0.25 & $20 \mathrm{~min} /$ day & $\begin{array}{l}\text { IL- } 4, \mathrm{IL}-13, \mathrm{IL}-17, \mathrm{OPG}, \mathrm{TGF}-\beta 1 \uparrow \\
\text { RANKL } \downarrow\end{array}$ \\
\hline Pravitharangul et al., 2018 & $\begin{array}{l}\text { Osteoblast-like cells from } \\
\text { iliac crest and mandibular bone } \\
\text { specimens }\end{array}$ & $0,30,60$ & 0.49 & 30 min/day & $\begin{array}{l}\text { IL }-6 \text { mRNA expression } \uparrow \\
\text { IL-1 } 1 \beta, \text { RANKL mRNA } \downarrow \\
\text { RANKL/OPG ratio } \downarrow \text { in iliac osteoblasts }\end{array}$ \\
\hline Haffner-Luntzer et al., 2018b & $\begin{array}{l}\text { MC3T3-E1 cells and primary } \\
\text { C57BL/6 mouse osteoblasts }\end{array}$ & 45 & 0.3 & $20 \mathrm{~min} /$ day & $\begin{array}{l}\text { Cytoskeletal remodeling: } \\
\text { actin content, actin fiber thickness } \uparrow \\
\text { Cell metabolic activity, cell proliferation } \uparrow \\
\text { ER } \alpha \text { signaling involved }\end{array}$ \\
\hline Apa et al., 2018 & Osteoblast like cells (SaOS-2) & $30,60,90$ & $\begin{array}{c}0.3 \\
1 \\
3\end{array}$ & $1 \mathrm{~h} /$ day & Proliferation $\downarrow(0.3 \mathrm{~g}, 30 \mathrm{~Hz})$ \\
\hline Gao et al., 2017 & Primary osteoblasts & 45 & 0.5 & 1 h/day, 3 days & $\begin{array}{l}\text { ALP, OCN, Runx2, BMP, OPG } \uparrow \\
\text { SOST } \downarrow \\
\text { Proliferation } \uparrow \text { Matrix mineralization } \uparrow \\
\text { Cytoskeletal remodeling } \\
\text { Wnt signaling involved }\end{array}$ \\
\hline Ota et al., 2016 & MC3T3-E1 & $30,60,90$ & $1.0-10 \mathrm{~m} / \mathrm{s}^{2}$ & & Runx2, Osterix, Col-1, ALP $\uparrow$ \\
\hline Rosenberg et al., 2002 & $\begin{array}{l}\text { Samples of cancellous bone } \\
\text { collected from femoral necks }\end{array}$ & $20,30,60$ & $1.0-10 \mathrm{~m} / \mathrm{s}^{2}$ & & $A L P \uparrow(30-60 \mathrm{~Hz})$ \\
\hline
\end{tabular}

TABLE 3 | LMHFV effects on osteoclasts.

\begin{tabular}{llcccl}
\hline References & Cells & Frequency $\mathbf{( H z )}$ & Magnitude $\left.{ }^{*}{ }^{*} \boldsymbol{g}\right)$ & Time schedule & Main outcome \\
\hline Sakamoto et al., 2019 & RAW264.7 & 48.3 & 0.5 & 1 min & $\begin{array}{l}\text { Proliferation } \uparrow \\
\text { No effect on osteoclast differentiation }\end{array}$ \\
Wu et al., 2012 & RAW264.7 & 45 & 0.3 & 15 min/day & $\begin{array}{l}\text { Inhibited actin ring formation } \\
\text { MMP-9, cathepsin K, TRAP mRNA } \downarrow \\
\text { RANKL-induced osteoclast differentiation } \downarrow\end{array}$ \\
\hline
\end{tabular}

of osteoblastic genes and osteogenic differentiation. In agreement with this finding, it was furthermore reported that LMHFV might alter lineage commitment of MSCs by inhibiting adipogenesis and promoting osteogenesis (Marycz et al., 2016; Baskan et al., 2017). This finding appears to be consistent regardless of the MSC origin or the vibration setting or duration. Because the culture conditions [two dimensional (2D) vs. three dimensional (3D)] are also known to influence MSC behavior and differentiation (Cukierman et al., 2002), some studies used 3D models (Zhou et al., 2011; Kim et al., 2012; Mehta, 2015; Chen et al., 2016), confirming the positive effect of LMHFV on osteogenic differentiation observed in $2 \mathrm{D}$ cultures. The study of Lau E. et al. (2011) reported inhibitory effects on osteogenesis, but this might be due to the relatively long vibration time of $1 \mathrm{~h} /$ day. Accumulating evidence also shows that LMHFV is able to increase MSC proliferation (Lau E. et al., 2011; Uzer et al., 2013; Demiray and Özçivici, 2015; Pongkitwitoon et al., 2016).

Cytoskeletal remodeling might be crucial for mechanotransduction (Helmke and Davies, 2002; Arnsdorf et al., 2009; Dahl et al., 2010). It was demonstrated by Uzer et al. $(2013,2015)$ that LMHFV upregulated actin-related genes and that a coupling between the nucleus and cytoskeleton is indispensable for amplifying the mechanoresponse and further promote cell signaling (Uzer et al., 2013, 2015).

\section{Osteoblasts and LMHFV}

Bone formation is mediated by osteoblasts, which are derived from MSCs through, among others, activation of the master transcription factor Runx2 (Cbfa1) (Komori et al., 1997). During osteoblast maturation, the cells undergo a differentiation process which is accompanied by extracellular matrix production and subsequent mineralization (Owen et al., 1990; Quarles et al., 1992; Lian and Stein, 1995). The terminal state of osteoblasts are osteocytes, which are long-living cells embedded into the bone matrix. Mechanical stimuli are crucial for osteogenesis and bone remodeling, while osteocytes (Lanyon, 1993) as well as osteoblasts (Neidlinger-Wilke et al., 1994) are considered to be mechanosensitive cells. Therefore, it appears likely that osteoblasts may be affected by LMHFV.

To assess the direct impact of vibration on osteoblasts, several studies were conducted using primary mouse osteoblasts or osteoblast-like cell lines (MC3T3-E1, SaOS-2) (Table 2). While applying vibration settings ranging over $30-60 \mathrm{~Hz}$ at $0.25-0.5 \mathrm{~g}$, cell proliferation, mineralization, cytoskeletal 
TABLE 4 | LMHFV effects on osteocytes.

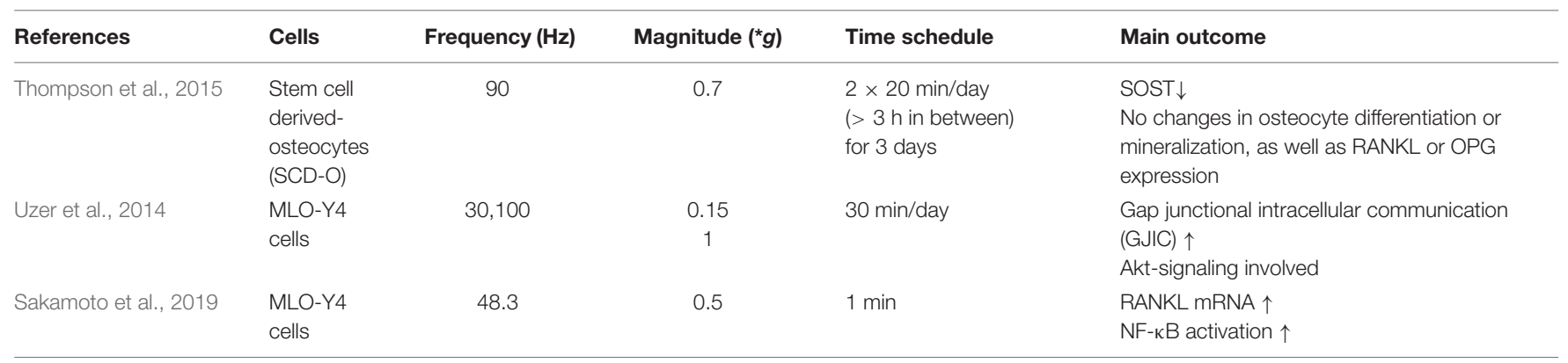

TABLE 5 | LMHFV effects on fracture healing using rat models.

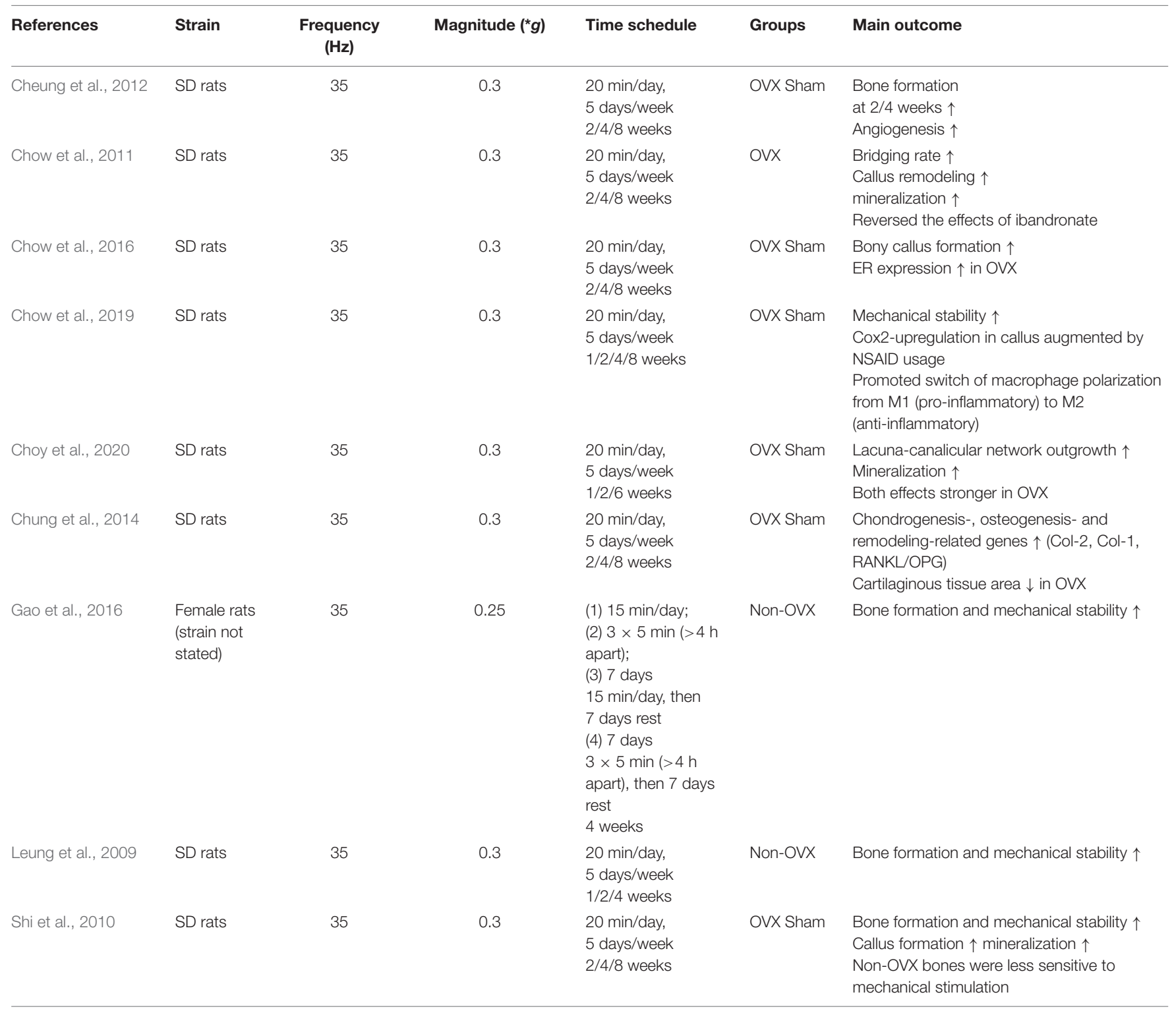

remodeling, and gene expression were evaluated. Gao et al. and Haffner-Luntzer et al. reported a significantly increased osteoblast proliferation in contrast to the study from Apa et al. showing decreased proliferation. This inconsistency might be due to the use of SasOS-2 cells (Apa et al., 2018) in comparison to primary osteoblasts (Gao et al., 2017) or MC3T3E1 cells (Haffner-Luntzer et al., 2018b), because SaOS-2 cells are already more differentiated. Quantitative Alizarin Red-S 
staining showed that also extracellular matrix mineralization was increased by LMHFV (Gao et al., 2017). Furthermore, gene and protein expression levels of osteogenesis-related mediators and pathways were evaluated. It was demonstrated that mechanical vibration significantly increased mRNA expression of ALP, OCN, Runx2, BMP, Osterix, type I collagen, and OPG, whereas SOST was downregulated (Ota et al., 2016; Gao et al., 2017). All these markers are important for bone formation and osteoblast differentiation, except SOST, which has the opposite effect. Therefore, LMHFV appears to accelerate osteogenic differentiation of osteoblasts. Moreover, the vibration treatment significantly increased gene expression levels of the Wnt signaling pathway members Wnt3a, Lrp6, and $\beta$-catenin (Gao et al., 2017), which are important for osteoblastogenesis. Using human iliac crest-derived mandible osteoblasts, Pravitharangul et al. reported that the RANKL/OPG mRNA ratio was reduced by LMHFV, suggesting an anti-resorptive cell response. Notably, another study by García-López et al. demonstrated decreased RANKL and increased IL-4, IL-13, IL-17, OPG, and TGF- $\beta$ levels. Using the conditioned medium from osteoblasts on osteoclasts, the authors demonstrated that osteoclasts were inhibited. These results confirm previous findings that LMHFV promotes osteogenesisassociated gene expression and reduces osteoclastic mediators.

Considering that external biophysical stimulation has been implicated in regulating actin cytoskeletal remodeling in MSCs, this was also examined in osteoblasts by Haffner-Luntzer et al. (2018b), showing that actin remodeling is increased by LMHFV treatment. In addition, Gao et al. demonstrated an increased number of microfilaments and thicker stress fibers in the vibrated group, suggesting that the vibration-induced effects on osteoblasts might be dependent on cytoskeletal rearrangement. Moreover, mechanotransduction in bone tissue is considered to be critically dependent on the presence of estrogen and its receptors (ERs) (Frost, 1987). Therefore, it was hypothesized that particularly ER $\alpha$ might be crucial for the effects of LMFHV on osteoblasts. Haffner-Luntzer et al. investigated the effects of $45 \mathrm{~Hz}(0.3 \mathrm{~g})$ vibrations on MC3T3-E1 cells in estrogen-free medium and demonstrated higher metabolic cell activity and increased Ptgs2 gene expression (Cox2) after LMHFV treatment, whereas these findings were reversed in the presence of estrogen. Cox 2 is known to be upregulated by mechanical strain and might be involved in osteoblast proliferation. To evaluate the role of $\mathrm{ER} \alpha$ in mechanotransduction, siRNA knockdown was performed to block $\mathrm{ER} \alpha$ signaling. In the absence of estrogen, it was demonstrated that $\mathrm{ER} \alpha$ is indeed required for the increased Ptgs2 gene expression and proliferation of MC3T3E1 cells after LMHFV suggesting that ligand-independent activity of $\mathrm{ER} \alpha$ is responsible for the vibration-induced effects. The same effect was observed by adding the selective ER $\alpha$ antagonist MPP dihydrochloride. Therefore, estrogen and the ER pathway appear to play an important role in LMHFV-mediated mechanotransduction.

In conclusion, LMHFV regulates osteoblast proliferation, differentiation, and matrix mineralization via upregulation of Wnt-related gene expression, cytoskeletal remodeling, and ER pathways. Furthermore, it appears to enhance the expression of osteoclast-inhibiting factors.

\section{Osteoclasts and LMHFV}

In addition to its indirect effects on osteoclastogenesis via upregulation of anti-osteoclastic factors in osteoblasts, LMHFV might also directly act on osteoclasts (Table 3 ). These cells derive from the monocyte/macrophage hematopoietic lineage and are essential for bone resorption. Osteoclast differentiation and activity are induced by RANKL binding; however, this can be attenuated by OPG, a soluble RANKL-binding decoy receptor (Simonet et al., 1997; Khosla, 2001). Therefore, RANKL is frequently used as a cell culture supplement to induce osteoclast differentiation in RAW246.7 cells in vitro (Hsu et al., 1999).

To determine whether LMHFV affects osteoclast functions, preosteoclastic murine RAW246.7 cells were subjected to LMHFV at $45 \mathrm{~Hz}(0.3 \mathrm{~g})$ for $15 \mathrm{~min} /$ day (Wu et al., 2012) and subsequently analyzed for TRAP-positive multinucleated cells (MNCs) and osteoclast-specific gene expression. Notably, LMHFV significantly reduced the formation of TRAP-positive MNCs and the upregulation of the osteoclastic genes cathepsin K, MMP-9, and TRAP. While TRAP and cathepsin K are essential for bone resorption, MMP-9 mediates the migration of precursor cells toward the bone. Furthermore, the number of formed actin rings, which represents an important osteoclast adhesion structure, was reduced by LMHFV (Wu et al., 2012). By contrast, Sakamoto et al. (2019) reported a significant increase in preosteoclastic RAW246.7 cell proliferation $48 \mathrm{~h}$ after vibration for $1 \mathrm{~min}$ at $48.3 \mathrm{~Hz}(0.5 \mathrm{~g})$. However, evaluation of TRAPpositive MNCs showed that osteoclast differentiation was not altered, which might be due to the fact that the cells only received one very short vibration treatment for $1 \mathrm{~min}$. In coculture experiments with RAW246.7 and previously vibrated osteocyte-like MLO-Y4 cells, the authors showed that osteoclast differentiation was significantly higher, which might be because of a significantly increased RANKL/OPG ratio in the supernatant of vibrated MLO-Y4 cells.

Although there are only three studies investigating the effects of LMHFV on osteoclasts, it appears that osteoclasts are rather inhibited in vitro. However, further studies investigating the involved underlying mechanism are needed.

\section{Osteocytes and LMHFV}

Osteocytes are derived from osteoblasts and are embedded into the mineralized bone matrix. They orchestrate bone remodeling by regulating osteoblast and osteoclast activity. Additionally, they secrete factors to stimulate or inhibit bone formation or resorption and they communicate with surrounding cells via dendritic processes through the lacunacanalicular system. Because osteocytes are considered as the main physiological mechanosensor in bone tissue, they might also be affected by LMHFV (Table 4).

To investigate the effects of LMHFV, Thompson et al. applied LMHFV $(90 \mathrm{~Hz}, 0.7 \mathrm{~g})$ to stem cell-derived osteocytes originating from BMSCs and found no changes in the osteocytic marker genes Dmp1, Fgf23, or E11, suggesting that LMHFV has no effect on osteocytic differentiation or mineralization. However, exposure to LMHFV significantly reduced SOST mRNA expression, but did not affect RANKL or OPG. Because SOST is a well-known inhibitor of osteoblastic bone formation, 
this suggests that LMHFV led to reduced osteocytes SOSTt expression and, therefore, increased osteoblastic bone formation.

By contrast, Sakamoto et al. reported enhanced RANKL mRNA expression by vibration of MLO-Y4 cells, whereas OPG levels were unaffected. This indicates an indirect positive effect of LMHFV on osteoclast differentiation via osteocytes. On the molecular level, GJIC through connexin 43 might be involved in vibration-induced cell mechanotransduction (Ziambaras et al., 1998; Cheng et al., 2001; Cherian et al., 2003; Batra et al., 2012). While Uzer et al. (2014) demonstrated that LMHFV $(0.15 \mathrm{~g}, 30 \mathrm{~Hz}, 30 \mathrm{~min} /$ day $)$ significantly increased GJIC between MLO-Y4 cells by 25\%, this effect was, however, dependent on Akt activation.

In conclusion, LMHFV appears to activate RANKL expression and to reduce SOST in osteocytes, whereas osteocytic differentiation marker genes are not directly affected.

\section{Influence of LMHFV on Bone Regeneration}

Bone regeneration after fracture requires a complex interplay between a variety of different cell types and biological mediators. In addition, an appropriate mechanical stimulation at the fracture site is considered to be essential for the healing process. Therefore, introducing external biomechanical stimuli by LMHFV is a promising strategy that might provoke positive effects on bone formation. In the following chapters, the influence of LMHFV on the early, intermediate, and late phases of fracture healing as well as on implant osseointegration is reviewed.

\section{Influence of LMHFV During the Early Inflammatory Phase After Fracture}

Within the early inflammatory phase, a complex interaction of several cell types and molecular mediators is essential for subsequent callus development and successful fracture repair. Danger- and pathogen-associated molecular patterns derived from the hematoma recruit neutrophils to the fracture site, which in turn release various mediators leading to the migration of macrophages, lymphocytes, and other immune cells. Macrophages together with neutrophils remove cell debris and secrete cytokines and chemokines to recruit progenitor cells and promote bone regeneration. The local inflammatory response is among others regulated by the pro-inflammatory mediators TNF- $\alpha$, IL-1, and IL- 6 and the anti-inflammatory IL-10 (Claes et al., 2012; Kovtun et al., 2016).

Only a few studies have investigated the effects of LMHFV on inflammation. Chow et al. investigated whether LMHFV influences the early inflammatory response after fracture in osteoporotic rats, because in estrogen-deficient, osteoporotic animal models, the innate immune response after fracture was shown to be altered (Chow et al., 2019). However, there is no clear consensus on whether the inflammation is lower (Chow et al., 2019) or rather increased (Haffner-Luntzer et al., 2017; Fischer et al., 2018). Chow et al. (2019) found that LMHFV induced a phenotype switch from pro-inflammatory M1 to pro-regenerative M2 macrophages. M2 macrophages were previously demonstrated to promote osteogenic differentiation of progenitor cells (Zhang et al., 2017); therefore, this could represent a mechanism by which LMHFV might influence the fracture healing outcome. The effect of vibration on other immune cell types and mediators that are involved in early inflammation has to date not been investigated.

The formation of new blood vessels (neo-angiogenesis) in the soft callus is important for bone repair. A decreased blood supply at the fracture site is associated with a compromised healing outcome in animal models and patients (Miclau et al., 2017; Haffner-Luntzer et al., 2019). Cheung et al. (2012) examined the effect of LMHFV on angiogenesis during fracture healing in rats and could demonstrate by 3D high-frequency power Doppler and microangiography that the vascular volume, blood flow, and angiogenesis were significantly higher in the LMHFV-treated rats compared to the sham-treated animals. In spite of the fact that neo-angiogenesis in OVX rats is compromised, this was attenuated by vibration in OVX rats. Because this is the only report on vascularization and LMHFV during fracture healing, more research is needed to verify the results and to gain further knowledge about the molecular mechanisms.

\section{Influence of LMHFV on Cartilaginous and Bony Callus Formation}

During endochondral fracture healing, a cartilaginous callus is formed at the fracture site to initially bridge the gap and provide some stability. During callus maturation, chondrocytes become hypertrophic, the cartilaginous matrix starts to calcify, and bone formation is initiated to replace the soft callus with bone. Because callus formation and maturation after fracture is highly relevant for successful healing and is significantly influenced by the biomechanical environment at the fracture site, applying mechanical stimulation by LMHFV could be beneficial for promoting fracture healing. Furthermore, because it is well known that OVX rodents and osteoporotic patients (Nikolaou et al., 2009) exhibit a significantly impaired callus maturation (Beil et al., 2010), many studies investigating the effects of LMHFV on fracture healing were performed with both OVX and sham-OVX rats or mice.

The majority of rat studies used a femur osteotomy model with internal fixation combined with a $35 \mathrm{~Hz}$ and $0.3 \mathrm{~g}$ vibration treatment (Table 5). Strikingly, all rat studies demonstrated that LMHFV application accelerates physiological fracture healing and it has been shown that LMHFV is further able to rescue OVXinduced impaired healing (Shi et al., 2010; Chung et al., 2014). LMHFV appears to promote callus formation by increasing both callus width and area between 1 and 3 weeks after fracture (Shi et al., 2010; Chow et al., 2011, 2016; Cheung et al., 2012). Histomorphometric analyses suggested that callus mineralization and maturation is also accelerated by LMHFV (Leung et al., 2009; Chung et al., 2014) because the amount osseous tissue was significantly higher while significantly less cartilage was formed in the vibration groups independently of the estrogen status of the animals (Chung et al., 2014). By contrast, a study by Shi et al. (2010) reported no changes in cartilage formation in OVX or sham-OVX rats on vibration treatment, which agrees with the finding of Leung et al. (2009) that a larger cartilage formation was only observed within the first week of vibration treatment, but not at later time points ( 2 or 4 weeks) in estrogen-competent rats. 
TABLE 6 | LMHFV effects on fracture healing using mouse models.

\begin{tabular}{|c|c|c|c|c|c|c|}
\hline References & Strain & Frequency (Hz) & Magnitude $\left({ }^{*} g\right)$ & Time schedule & Groups & Main outcome \\
\hline Haffner-Luntzer et al., 2018a & $\begin{array}{l}\mathrm{ER} \alpha-\mathrm{KO} \\
\mathrm{ER} \beta-\mathrm{KO} \\
(\mathrm{C} 57 \mathrm{BL} / 6)\end{array}$ & 45 & 0.3 & $\begin{array}{l}20 \text { min/day, } 5 \text { days/week } \\
3 \text { weeks }\end{array}$ & OVX Sham & $\begin{array}{l}\text { Flexural rigidity } \uparrow \\
\text { ER } \alpha \text { required for beneficial } \\
\text { effect of LMHFV on healing } \\
\text { in OVX mice }\end{array}$ \\
\hline Wehrle et al., 2014 & $\begin{array}{l}\text { C57BL/6 } \\
\text { (12 weeks) }\end{array}$ & 35,45 & 0.3 & $\begin{array}{l}20 \text { min/day, } 5 \text { days/week } \\
10 \text { days or } 3 \text { weeks }\end{array}$ & Non-OVX & $\begin{array}{l}35 \mathrm{~Hz} \text { : } \\
\text { no effect } \\
45 \mathrm{~Hz} \text { : } \\
\text { flexural rigidity } \downarrow \\
\text { bone formation in the } \\
\text { fracture callus } \downarrow\end{array}$ \\
\hline Wehrle et al., 2015 & $\begin{array}{l}\text { C57BL/6 } \\
\text { (49 weeks) }\end{array}$ & 45 & 0.3 & $\begin{array}{l}20 \text { min/day, } 5 \text { days/week } \\
10 \text { days or } 3 \text { weeks }\end{array}$ & OVX Sham & $\begin{array}{l}\text { Flexural rigidity } \uparrow \text { in OVX } \\
\text { Bone formation } \uparrow \text { in OVX }\end{array}$ \\
\hline Zhang et al., 2020 & $\begin{array}{l}\text { SAMP8, } \\
\text { non-sarcopenic } \\
\text { SAMR1 }\end{array}$ & 35 & 0.3 & $\begin{array}{l}20 \mathrm{~min} / \text { day, } 5 \text { days/week } \\
\text { 2/4/6 weeks }\end{array}$ & Non-OVX & $\begin{array}{l}\text { Callus formation } \uparrow \\
\text { Callus remodeling } \uparrow \\
\text { Mechanical properties } \uparrow \\
\text { in non-sarcopenic mice }\end{array}$ \\
\hline
\end{tabular}

TABLE 7 | LMHFV effects on fracture healing using sheep models.

\begin{tabular}{|c|c|c|c|c|c|}
\hline References & Species & Frequency (Hz) & Magnitude $\left({ }^{*} g\right)$ & Time schedule & Main outcome \\
\hline Li et al., 2018 & Small-tail Han sheep & 35 & 0.25 & $\begin{array}{l}15 \mathrm{~min} / \text { day continuous or intermittent } \\
\text { at } 1,3,5,7,14 \text { days } \\
\text { Start: } 14 \text { days post-OP }\end{array}$ & $\begin{array}{l}\text { Callus formation } \uparrow \text { mechanical } \\
\text { properties } \uparrow \\
\mathrm{Ca}, \mathrm{P}, \mathrm{Ca} / \mathrm{P} \text { ratio } \uparrow\end{array}$ \\
\hline Mu et al., 2019 & Short-tailed Han sheep & 35 & 0.25 & $\begin{array}{l}15 \mathrm{~min} / \text { day continuous or } \\
\text { intermittent at } 1,2,3,5,7,17 \text { days } \\
\text { Start: } 14 \text { days post-OP }\end{array}$ & Callus formation $\uparrow$ \\
\hline Tan et al., 2016 & Short-tailed Han sheep & 35 & 0.25 & $\begin{array}{l}15 \mathrm{~min} / \text { day or intermittent at } 7 \text { days } \\
\text { Start: } 14 \text { days post-OP }\end{array}$ & $\begin{array}{l}\text { Callus volume } \uparrow \\
\text { Bone elastic modulus } \uparrow \\
\mathrm{Ca}, \mathrm{P}, \mathrm{Ca} / \mathrm{P} \text { ratio } \uparrow\end{array}$ \\
\hline Tan et al., 2017 & Small-tail sheep & 35 & 0.3 & $\begin{array}{l}20 \mathrm{~min} / \text { day } \\
\text { intermittent at } 1,3,5 \text { or } 7 \text { days } \\
\text { Start: } 7 \text { days post-OP }\end{array}$ & $\begin{array}{l}\text { Callus width and area } \uparrow \\
\text { week } 4 \text { : } \\
\text { ALP, BGP, TGF } \beta 1 \uparrow \\
\text { TRAP5b } \downarrow \\
\text { week 8: } \\
\text { TGF } \beta 1 \uparrow \\
\text { TRAP5b } \downarrow\end{array}$ \\
\hline
\end{tabular}

In mice, LMHFV improved fracture healing only in OVX animals (Table 6), while in estrogen-competent mice, delayed healing was observed (Wehrle et al., 2014). In detail, Wehrle et al. demonstrated that the flexural rigidity and bone formation in the fracture callus were significantly decreased in estrogencompetent mice that received a vibration treatment of $45 \mathrm{~Hz}$ at $0.3 \mathrm{~g}$ acceleration. Interestingly, the application of $35 \mathrm{~Hz}$ had no effect on the fracture callus, highlighting that the vibration frequency is a crucial parameter that should be carefully considered. By contrast, LMHFV with $45 \mathrm{~Hz}$ and $0.3 \mathrm{~g}$ significantly increased flexural rigidity and bone formation in the fracture callus in estrogen-deficient, OVX mice (Wehrle et al., 2015). Therefore, estrogen appears to play a crucial role in mediating the effects of LMHFV on bone healing. On a molecular level, the expression of ERs appears to play an important role in the context of accelerated fracture healing induced by LMHFV. It was shown that ER $\alpha$ expression was enhanced by LMHFV only in the fracture callus of OVX mice (Wehrle et al., 2015) and OVX rats (Chow et al., 2016), both, on the mRNA and protein levels. This might explain the higher mechanical sensitivity of osteoporotic bone toward LMHFV, because ER $\alpha$ is suggested to have a mechanosensory function. By contrast, ER $\beta$ expression was upregulated by LMHFV in sham-OVX mice. A study performed by Haffner-Luntzer et al. (2018a) used both global $\mathrm{ER} \alpha$ and $\mathrm{ER} \beta$ knockout mice with a femur diaphysis osteotomy model and a vibration regime of $45 \mathrm{~Hz}$ and $0.3 \mathrm{~g}$ to evaluate the role of ERs in vibration-induced effects on bone regeneration. Biomechanical testing and micro-computed tomography analysis revealed that $\mathrm{ER} \alpha$ is required for the effects of LMHFV on fracture healing both in sham-OVX and OVX mice, whereas ER $\beta$ was shown to play a minor role.

In large animals like sheep, several studies confirmed that LMHFV can improve fracture healing in a metatarsal osteotomy model (Table 7). Li et al. (2018) and $\mathrm{Mu}$ et al. (2019) compared the efficacy of intermittent and continuous vibration and showed that LMHFV had the greatest effect in the 7day interval group $(71.4 \%$ recovery with grade 3 healing vs. $42.9 \%$ in the continuous treatment group and $14.3 \%$ in the natural healing group without vibration. Callus volumes were also significantly increased in the 7-day interval group 
TABLE 8 | LMHFV effects on osseointegration of implants.

\begin{tabular}{|c|c|c|c|c|c|c|}
\hline References & Strain & Frequency $(\mathrm{Hz})$ & Magnitude $\left({ }^{*} g\right)$ & Time schedule & Implant & Study outcome \\
\hline Chen et al., 2012 & SD rats & 30-35 & 0.3 & $\begin{array}{l}20 \mathrm{~min} / \text { day, and } 5 \text { days/week } \\
8 \text { weeks }\end{array}$ & $\begin{array}{l}\text { Hydroxyapatite } \\
\text { (HA)-coated titanium } \\
\text { implants (proximal tibia) }\end{array}$ & $\begin{array}{l}\mathrm{BIC}, \mathrm{BF} \uparrow \\
\text { but effects are weaker than } \\
\text { alendronate } \\
\text { Max. push out force } \uparrow\end{array}$ \\
\hline Jing et al., 2015 & $\begin{array}{l}\text { Female New Zealand } \\
\text { rabbits }\end{array}$ & 30 & 0.5 & $1 \mathrm{~h} /$ day for 6 or 12 weeks & $\begin{array}{l}\text { Porous titanium alloy } \\
\text { (Ti6Al4V) (femoral condyle) }\end{array}$ & $\begin{array}{l}\text { Bone ingrowth within pores of } \\
\text { the implant } \uparrow \\
\text { BV/TV } \uparrow \\
\text { Tb. N } \uparrow \text { ALP, OCN, Runx2, } \\
\text { BMP2, OPG } \uparrow \\
\text { SOST, RANKL } \downarrow\end{array}$ \\
\hline Liang et al., 2014 & SD rats & 45 & 0.2 & $30 \mathrm{~min} /$ day & $\begin{array}{l}\text { Titanium implant } \\
\text { (metaphyseal tibia) }\end{array}$ & $\begin{array}{l}\mathrm{BF}, \mathrm{BIC} \uparrow \\
\text { thickness of the bone lamellae } \\
\text { (TBL) } \uparrow \\
\mathrm{BMD} \uparrow \\
\text { removal torque } \uparrow\end{array}$ \\
\hline Ogawa et al., 2011b & Wistar rats & $\begin{array}{l}15 \text { consecutive frequency } \\
\text { steps }(12,20,30, \ldots, 150 \\
\mathrm{Hz})\end{array}$ & 0.3 & $\begin{array}{l}11 \mathrm{~min} / \text { day } 5 \text { days/week } \\
3,7,14,25 \text { days }\end{array}$ & $\begin{array}{l}\text { Custom-made titanium } \\
\text { implant (proximal } \\
\text { metaphysis) }\end{array}$ & $\mathrm{BIC}, \mathrm{BF} \uparrow$ \\
\hline Ogawa et al., 2011a & Male Wistar rats & $\begin{array}{l}15 \text { consecutive frequency } \\
\text { steps }(12,20,30, \ldots, 150 \\
\mathrm{Hz})\end{array}$ & 0.3 & $\begin{array}{l}1.25,2.5,5 \text { and } 2 \times 1.25 \mathrm{~min} \\
(>4 \mathrm{~h})\end{array}$ & $\begin{array}{l}\text { Custom-made titanium } \\
\text { implant (medio-proximal } \\
\text { site of tibia) }\end{array}$ & $\begin{array}{l}\mathrm{BIC} \uparrow \\
2 \times 1.25 \text { min most pronounced } \\
\text { effect }\end{array}$ \\
\hline Ogawa et al., 2014 & Male Wistar rats & $12-30 / 70-90 / 130-150$ & $0.3 / 0.075 / 0.043$ & $1 / 4$ weeks & $\begin{array}{l}\text { Titanium implant } \\
\text { (metaphyseal tibia) }\end{array}$ & $\begin{array}{l}\mathrm{BIC} \uparrow \\
\mathrm{BV} / T \mathrm{~V} \uparrow\end{array}$ \\
\hline Ruppert et al., 2018 & SD rats & 55 & $\begin{array}{l}0,0.15,0.3,0.6 \text {, or } \\
1.2\end{array}$ & 6 weeks & Titanium implant (tibia) & $\mathrm{BF} \uparrow$ \\
\hline Shibamoto et al., 2018 & Wistar rats & 50 & 0.5 & $\begin{array}{l}15 \mathrm{~min} / \text { day } \\
5 \text { days/week }\end{array}$ & $\begin{array}{l}\text { Titanium implant } \\
\text { (metaphyseal tibia) }\end{array}$ & $\begin{array}{l}\mathrm{BIC} \uparrow \\
\mathrm{LMHF}+\mathrm{PTH} \text { had additive } \\
\text { effects in OVX rats } \\
\text { removal torque } \uparrow\end{array}$ \\
\hline Zhou et al., 2015 & SD rats & 40 & 0.3 & $\begin{array}{l}30 \mathrm{~min} / 12 \mathrm{~h} \\
5 \text { days/week } \\
\text { for } 12 \text { weeks }\end{array}$ & $\begin{array}{l}\text { Hydroxyapatite-coated } \\
\text { titanium implants } \\
\text { (medio-proximal site of } \\
\text { tibia) }\end{array}$ & $\begin{array}{l}\text { BV/TV, Tb.N, Tb. Th } \uparrow \\
\text { Runx2, OPN, OC } \uparrow \\
\text { RANKL } \downarrow\end{array}$ \\
\hline
\end{tabular}


TABLE 9 | LMHFV and involved molecular signaling pathways.

\begin{tabular}{ll}
\hline References & Pathways \\
\hline Chow et al., 2016, 2019 & $\begin{array}{l}\text { Estrogen receptor (ER) } \\
\text { Cox-2/prostaglandin signaling }\end{array}$ \\
Demiray and Özçivici, 2015 & Cytoskeletal remodeling \\
Gao et al., 2017 & Wnt signaling \\
Haffner-Luntzer et al., 2018a,b & Cytoskeletal remodeling \\
& ER $\alpha$ \\
Li et al., 2019 & ERoskeletal remodeling \\
Sakamoto et al., 2019 & Activation of the canonical Wnt pathway \\
Uzer et al., 2013, 2014, 2015 & NF-kB \\
& Cytoskeletal remodeling \\
Zhou et al., 2011 & Akt signaling \\
& ERK1/2 signaling \\
\hline
\end{tabular}

(Li et al., 2018), confirming the results in rodents. By contrast, Tan et al. (2017) found that the vibration treatment with 1-day intermittence had the greatest positive effect on fracture healing. This discrepancy could be explained by the 1-week earlier vibration initiation in the study by Tan et al. and the slightly different vibration settings which might lead to differences in the healing outcome. On a molecular level, increased serum levels of bone remodeling markers (BALP, BGP, TRAP) as well as of endochondral ossification markers (TGF $\beta 1$ ) were found in all vibration groups.

In conclusion, the majority of studies both in small and large animal models demonstrated that LMHFV is able to accelerate fracture healing by increasing bone formation in the fracture callus. In mice, the effects of LMHFV appear to be highly dependent on the estrogen status of the animals. In this model organism, LMHFV provoked negative effects on fracture healing in estrogen-competent animals, whereas it improved healing in estrogen-deficient, osteoporotic animals. Further research is needed to investigate the underlying molecular mechanisms.

\section{Influence of LMHFV on Callus Remodeling}

Following bony bridging of the fracture gap, the external callus is continually remodeled by osteoclasts until the normal bone structure and shape are restored. Because osteoclasts were shown to be target cells of LMHFV in vitro (Wu et al., 2012; Sakamoto et al., 2019), vibration treatment might influence callus remodeling during fracture healing.

Shi et al. (2010) and Chung et al. (2014) showed that LMHFV induced more rapid callus remodeling particularly in OVX rats by upregulation of the RANKL/OPG ratio. The same authors investigated whether LMHFV influences callus remodeling in OVX rats by combining the vibration treatment with ibandronate administration, a bisphosphonate which inhibits osteoclast activity (Chow et al., 2011). As expected, bone remodeling was reduced in the animals treated with ibandronate alone. Notably, the combination of the anti-resorptive therapy with LMHFV ameliorated the effects of the bisphosphonate on callus remodeling. However, the authors did not evaluate osteoclast numbers or activity directly; therefore, drawing a valid conclusion about the effects of LMHFV on osteoclasts in vivo was not possible. By contrast, Haffner-Luntzer et al. did evaluate osteoclast numbers, but could not observe any effect of LMHFV both under estrogen-deficient or estrogen-competent conditions.

\section{Influence of LMHFV on Osseointegration of Bone Implants}

Bone implant osseointegration is a critical step toward preventing implant failure during bone regeneration. The implant material and its surface characteristics are major factors which might positively influence recruitment and differentiation of osteogenic cells to the implant surface to avoid implant loosening. Furthermore, the mechanical conditions at the bone-implant interface crucially influence bone regeneration and osseointegration (Albrektsson and Jacobsson, 1987; Hudieb et al., 2011). External biophysical stimulation by LMHFV might be an option to optimize osseointegration, because its anabolic potential for bone has already been demonstrated in numerous studies.

To examine the effect of LMHFV during implant osseointegration, rat models with titanium implants and a vibration regime of $0.2-0.5 \mathrm{~g}$ and $30-45 \mathrm{~Hz}$ have been used (Table 8). In response to LMHFV, all studies observed a significant increase in bone formation around the used implants (Ogawa et al., 2011a,b, 2014; Jing et al., 2015, 2018; Ruppert et al., 2018), even with the slightly different loading protocols that were applied. Bone volume to tissue volume ratio around the implant was analyzed by $\mu \mathrm{CT}$ scanning, whereas histomorphometrical analysis analyzed bone formation directly by fluorescence labeling of the newly build bone. Beyond that, LMHFV application significantly increased the bone mineral density in the bone-implant interface in the group that did receive LMHFV treatment (Liang et al., 2014), as analyzed by $\mu \mathrm{CT}$ scanning. These findings were further strengthened by biomechanical testing, which demonstrated significantly increased removal torque in the vibration group compared to the control animals (Liang et al., 2014).

Further studies investigated whether LMHFV is also capable of improving osseointegration in osteoporotic animals (Chen et al., 2012; Liang et al., 2014; Shibamoto et al., 2018). Indeed, LMHFV rescued OVX-induced compromised implant osseointegration by increasing the bone contact to the implant, the amount of newly formed bone and the shear strength at the interface (Chen et al., 2012; Liang et al., 2014; Shibamoto et al., 2018). This was demonstrated by histomorphometrical analysis.

Chen et al. treated OVX rats with LMHFV or by bisphosphonate alendronate administration and demonstrated that both treatments significantly increased osseointegration; however, the effects of LMHFV were less compared to alendronate. Hypothesizing that LMHFV and antiosteoporosis medications might have additive effects on implant osseointegration, Shibamoto et al. compared the effects of PTH or alendronate treatment in OVX rats with or without LMHFV vibration. Only PTH and LMHFV displayed positive additive effects on implant integration (Chen et al., 2012). 
Jing et al. (2015) analyzed the expression of osteogenic markers genes in rabbits which were subjected to LMHFV for 6 or 12 weeks. The osteogenesis-related genes Alpl, Bglap, Runx2, Bmp2, and Opg were upregulated, suggesting that LMHFV promotes osteoblastogenesis and mineralization. The osteoanabolic canonical Wnt pathway also appears to be activated, because Wnt3a, Lrp6, and $\beta$-catenin were expressed significantly higher in the LMHFV group, whereas antiosteogenic SOST expression was significantly reduced (Chen et al., 2016). Moreover, the mRNA levels of osteoclastogenesisassociated Rankl were significantly reduced. Furthermore, ERK1/2 signaling, which is known to inhibit osteoclast activity, was shown to be upregulated after LMHFV (Zhou et al., 2015). In conclusion, LMHFV appears to activate osteogenic and to inhibit osteoclastogenic pathways. Nonetheless, further studies are needed to fully elucidate the mechanisms of vibrationinduced bone formation around implants.

In summary, LMHFV improved osseointegration of titanium implants in estrogen-competent and deficient animal models by promoting osteoblastogenesis and exhibiting antiresorptive effects.

\section{CONCLUSION}

Mechanical stimuli are considered to be essential regulators in bone remodeling and regeneration. Therefore, external biophysical stimulation with LMHFV could possibly be used to enhance bone formation. It is supposed not to cause any side effects and can be readily applied by whole-body vibration.

Indeed, the first clinical studies demonstrated improved bone mineral density and bone mass after LMHFV in both healthy and osteoporotic patients. Underlying mechanisms have been extensively studied in vitro and in vivo. Most of the in vitro experiments showed that LMHFV is able to enhance MSC and osteoblast proliferation. Furthermore, osteogenic differentiation of MSCs and osteoblasts was shown to be accelerated by LMHFV. One important mechanosensitive pathway mediating the effects of LMHFV might be the Wnt/beta-catenin signaling pathway. Furthermore, it was demonstrated that ER signaling plays a crucial role particularly on osteoblasts. Ligand-dependent ER signaling might rather act negatively on osteogenic cell proliferation, whereas ligand-independent ER signaling mediated positive LMHFV effects. Additionally, cytoskeletal remodeling was induced by LMHFV, which might influence MSCs cell fate decision, proliferation, and differentiation. In addition to the effects of LMHFV on osteogenic cells, vibration treatment appears to inhibit osteoclast formation and activity directly and indirectly by reduced osteoclastogenic mediator release from osteoblasts.

During fracture healing, LMHFV may also exert diverse effects on the involved cell types. Vibration was shown to modulate macrophage polarization and enhance vascularization. Furthermore, LMHFV increased bone formation in the fracture callus. However, some studies demonstrated that this was only the case in estrogen-deficient, osteoporotic animals and that ER signaling was crucial for those effects. Therefore, attention has to be paid when transferring LMHFV to the clinical situation, because only specific fracture patient cohorts might benefit from whole-body vibration. Further research is needed to understand the involved molecular mechanisms, side effects, and potential benefits for patients. Before vibration can be recommended as a new treatment option for fractures, more clinical studies are needed to examine the efficacy, regimes, and safety for fracture healing. To date, there are no related clinical studies published in PubMed; however, two studies on that topic are registered at clinicaltrials.gov. In addition to its effects on fracture healing, LMHFV demonstrated positive effects on the osseointegration of orthopedic implants by increasing BIC and BF. Moreover, in this context, osteoanabolic Wnt/beta-catenin signaling was shown to mediate positive effects of LMHFV on bone formation. Furthermore, diminished osteoclastogenesis by reduced RANKL expression of osteoblasts was demonstrated.

In conclusion, LMHFV might be a promising treatment strategy to improve bone regeneration during fracture healing and implant integration. However, more research is needed to elucidate the involved molecular signaling pathways, since not much is known how LMHFV transduce mechanical stimulation into biochemical signals (Table 9). In particular, the ER signaling pathway was demonstrated to play a double-faced role by mediating negative effects of LMHFV on osteoblasts in the presence of estrogen, but positive effects in its absence. This might account for differences in fracture healing outcome after LMHFV in estrogen-competent and estrogen-deficient mice. Clinical trials are needed to investigate the translational potential of LMHFV and to define fracture patient cohorts which might benefit from this treatment. Indeed, some clinical trials showed a beneficial outcome of LMHFV on bone parameters (Rubin et al., 2004; Ward et al., 2004), whereas others demonstrated no effect of the vibration (Slatkovska et al., 2010; Lau R. et al., 2011). This might be due to different patient cohorts, but also due to different vibration regimes and ways to apply the biomechanical stimulation demonstrating how important it is to apply LMHFV in a very precise and controllable manner.

\section{AUTHOR CONTRIBUTIONS}

LS conducted the systematic literature research. LS and MH-L drafted the manuscript. All authors worked on the final version of the manuscript.

\section{FUNDING}

The project (20-42) was supported by a literature grant from the ON Foundation, Switzerland. Further, the authors were funded by the German Research Foundation (DFG, 9 HA 8470/1-1). 


\section{REFERENCES}

Albrektsson, T., and Jacobsson, M. (1987). Bone-metal interface in osseointegration. J. Prosthet. Dent. 57, 597-607. doi: 10.1016/0022-3913(87) 90344-90341

Apa, L., Urciuoli, E., D’Alvia, L., Peruzzi, B., Del Prete, Z., and Rizzuto, E. (2018). "Development and mechanical validation of an in vitro system for bone cell vibration loading," in Proceedings of the MeMeA 2018 - 2018 IEEE International Symposium on Medical Measurements and Applications, Rome.

Arnsdorf, E. J., Tummala, P., Kwon, R. Y., and Jacobs, C. R. (2009). Mechanically induced osteogenic differentiation - The role of RhoA, ROCKII and cytoskeletal dynamics. J. Cell Sci. 122, 546-553. doi: 10.1242/jcs.036293

Baskan, O., Mese, G., and Ozcivici, E. (2017). Low-intensity vibrations normalize adipogenesis-induced morphological and molecular changes of adult mesenchymal stem cells. Proc. Inst. Mech. Eng. Part H J. Eng. Med. 231, 160-168. doi: 10.1177/0954411916687338

Batra, N., Burra, S., Siller-Jackson, A. J., Gu, S., Xia, X., Weber, G. F., et al. (2012). Mechanical stress-activated integrin $\alpha 5 \beta 1$ induces opening of connexin 43 hemichannels. Proc. Natl. Acad. Sci. U. S. A. 109, 3359-3364. doi: 10.1073/ pnas.1115967109

Beil, F. T., Barvencik, F., Gebauer, M., Seitz, S., Rueger, J. M., Ignatius, A., et al. (2010). Effects of estrogen on fracture healing in mice. J. Trauma Inj. Infect. Crit. Care 69, 1259-1265. doi: 10.1097/TA.0b013e3181c4544d

Chen, B., Li, Y., Xie, D., and Yang, X. (2012). Low-magnitude high-frequency loading via whole body vibration enhances bone-implant osseointegration in ovariectomized rats. J. Orthop. Res. 30, 733-739. doi: 10.1002/jor.22004

Chen, B., Lin, T., Yang, X., Li, Y., Xie, D., Zheng, W., et al. (2016). Lowmagnitude, high-frequency vibration promotes the adhesion and the osteogenic differentiation of bone marrow-derived mesenchymal stem cells cultured on a hydroxyapatite-coated surface: the direct role of $\mathrm{Wnt} /$ catenin signaling pathway activation. Int. J. Mol. Med. 38, 1531-1540. doi: 10.3892/ijmm.2016.2757

Cheng, B., Zhao, S., Luo, L. F., Sprague, E., Bonewald, L. F., and Jiang, J. X. (2001). Expression of functional gap junctions and regulation by fluid flow in osteocytelike MLO-Y4 cells. J. Bone Miner. Res. 16, 249-259. doi: 10.1359/jbmr.2001.16. 2.249

Cherian, P. P., Cheng, B., Gu, S., Sprague, E., Bonewald, L. F., and Jiang, J. X. (2003). Effects of mechanical strain on the function of gap junctions in Osteocytes are mediated through the prostaglandin EP2 receptor. J. Biol. Chem. 278, 43146-43156. doi: 10.1074/jbc.M302993200

Cheung, W. H., Sun, M. H., Zheng, Y. P., Chu, W. C. W., Leung, A. H. C., Qin, L., et al. (2012). Stimulated angiogenesis for fracture healing augmented by lowmagnitude, high-frequency vibration in A rat model-evaluation of pulsed-wave doppler, 3-D power doppler ultrasonography and micro-CT microangiography. Ultrasound Med. Biol. 38, 2120-2129. doi: 10.1016/j.ultrasmedbio.2012.07.025

Chow, D. H.-K., Leung, K.-S., Qin, L., Leung, A. H.-C., and Cheung, W.-H. (2011). Low-magnitude high-frequency vibration (LMHFV) enhances bone remodeling in osteoporotic rat femoral fracture healing. J. Orthop. Res. 29, 746-752. doi: 10.1002/jor.21303

Chow, S. K. H., Chim, Y. N., Wang, J., Zhang, N., Wong, R. M. Y., Tang, N., et al. (2019). Vibration treatment modulates macrophage polarisation and enhances early inflammatory response in oestrogen-deficient osteoporoticfracture healing. Eur. Cells Mater. 38, 228-245. doi: 10.22203/eCM.v03 $8 \mathrm{a} 16$

Chow, S. K. H., Leung, K. S., Qin, J., Guo, A., Sun, M., Qin, L., et al. (2016). Mechanical stimulation enhanced estrogen receptor expression and callus formation in diaphyseal long bone fracture healing in ovariectomy-induced osteoporotic rats. Osteoporos. Int. 27, 2989-3000. doi: 10.1007/s00198-0163619-3612

Choy, M. V., Wong, R. M., Li, M. C., Wang, B. Y., Liu, X. D., Lee, W., et al. (2020). Can we enhance osteoporotic metaphyseal fracture healing through enhancing ultrastructural and functional changes of osteocytes in cortical bone with low-magnitude high-frequency vibration? FASEB J. 34, 4234-4252. doi: 10.1096/fj.201901595R

Chung, S.-L., Leung, K.-S., and Cheung, W.-H. (2014). Low-magnitude highfrequency vibration enhances gene expression related to callus formation, mineralization and remodeling during osteoporotic fracture healing in rats. J. Orthop. Res. 32, 1572-1579. doi: 10.1002/jor.22715
Claes, L., Recknagel, S., and Ignatius, A. (2012). Fracture healing under healthy and inflammatory conditions. Nat. Rev. Rheumatol. 8, 133-143. doi: 10.1038/ nrrheum.2012.1

Claes, L., Reusch, M., Göckelmann, M., Ohnmacht, M., Wehner, T., Amling, M., et al. (2011). Metaphyseal fracture healing follows similar biomechanical rules as diaphyseal healing. J. Orthop. Res. 29, 425-432. doi: 10.1002/jor.21227

Cukierman, E., Pankov, R., and Yamada, K. M. (2002). Cell interactions with threedimensional matrices. Curr. Opin. Cell Biol. 14, 633-640. doi: 10.1016/S09550674(02)00364-362

Dahl, K. N., Booth-Gauthier, E. A., and Ladoux, B. (2010). In the middle of it all: mutual mechanical regulation between the nucleus and the cytoskeleton. J. Biomech. 43, 2-8. doi: 10.1016/j.jbiomech.2009.09.002

Demiray, L., and Özçivici, E. (2015). Bone marrow stem cells adapt to lowmagnitude vibrations by altering their cytoskeleton during quiescence and osteogenesis. Turkish J. Biol. 39, 88-97. doi: 10.3906/biy-1404-1435

Dubosc-Marchenay, N., Lacombe, F., Dumain, P., Marit, G., Montastruc, M., Belloc, F., et al. (1992). Role of blast cell immunophenotyping for the diagnosis and prognosis of acute myeloid leukemia. Hematol. Oncol. 10, 235-249. doi: 10.1002/hon.2900100502

Fischer, V., Kalbitz, M., Müller-Graf, F., Gebhard, F., Ignatius, A., Liedert, A., et al. (2018). Influence of menopause on inflammatory cytokines during murine and human bone fracture healing. Int. J. Mol. Sci. 19:2070. doi: 10.3390/ ijms 19072070

Frost, H. M. (1987). Bone "mass" and the "mechanostat": a proposal. Anat. Rec. 219, 1-9. doi: 10.1002/ar.1092190104

Gao, J., Gong, H., Huang, X., Zhang, R., Ma, R., Zhu, D., et al. (2016). Multilevel assessment of fracture calluses in rats subjected to low-magnitude highfrequency vibration with different rest periods. Ann. Biomed. Eng. 44, 24892504. doi: 10.1007/s10439-015-1532-Z

Gao, H., Zhai, M., Wang, P., Zhang, X., Cai, J., Chen, X., et al. (2017). Lowlevel mechanical vibration enhances osteoblastogenesis via a canonical Wnt signaling-associated mechanism. Mol. Med. Rep. 16, 317-324. doi: 10.3892/ mmr.2017.6608

García-López, S., Villanueva, R. E., Massó-Rojas, F., Páez-Arenas, A., and Meikle, M. C. (2020). Micro-vibrations at $30 \mathrm{~Hz}$ on bone cells cultivated in vitro produce soluble factors for osteoclast inhibition and osteoblast activity. Arch. Oral. Biol. 110:104594. doi: 10.1016/j.archoralbio.2019.104594

Haffner-Luntzer, M., Fischer, V., Prystaz, K., Liedert, A., and Ignatius, A. (2017). The inflammatory phase of fracture healing is influenced by oestrogen status in mice. Eur. J. Med. Res. 22, 1-11. doi: 10.1186/s40001-017-0264-y

Haffner-Luntzer, M., Hankenson, K. D., Ignatius, A., Pfeifer, R., Khader, B. A., Hildebrand, F., et al. (2019). Review of animal models of comorbidities in fracture-healing research. J. Orthop. Res. 37, 2491-2498. doi: 10.1002/jor.24 454

Haffner-Luntzer, M., Kovtun, A., Lackner, I., Mödinger, Y., Hacker, S., Liedert, A., et al. (2018a). Estrogen receptor $\alpha$ - $(\mathrm{ER} \alpha)$, but not $\mathrm{ER} \beta$-signaling, is crucially involved in mechanostimulation of bone fracture healing by whole-body vibration. Bone 110, 11-20. doi: 10.1016/j.bone.2018.01.017

Haffner-Luntzer, M., Lackner, I., Liedert, A., Fischer, V., and Ignatius, A. (2018b). Effects of low-magnitude high-frequency vibration on osteoblasts are dependent on estrogen receptor $\alpha$ signaling and cytoskeletal remodeling. Biochem. Biophys. Res. Commun. 503, 2678-2684. doi: 10.1016/j.bbrc.2018.08. 023

Helmke, B. P., and Davies, P. F. (2002). The cytoskeleton under external fluid mechanical forces: hemodynamic forces acting on the endothelium. Ann. Biomed. Eng. 30, 284-296. doi: 10.1114/1.1467926

Hsu, H., Lacey, D. L., Dunstan, C. R., Solovyev, I., Colombero, A., Timms, E., et al. (1999). Tumor necrosis factor receptor family member RANK mediates osteoclast differentiation and activation induced by osteoprotegerin ligand. Proc. Natl. Acad. Sci. U.S.A. 96, 3540-3545. doi: 10.1073/pnas.96.7.3540

Hudieb, M. I., Wakabayashi, N., and Kasugai, S. (2011). Magnitude and direction of mechanical stress at the osseointegrated interface of the microthread implant. J. Periodontol. 82, 1061-1070. doi: 10.1902/jop.2010.100237

Jing, D., Tong, S., Zhai, M., Li, X., Cai, J., Wu, Y., et al. (2015). Effect of low-level mechanical vibration on osteogenesis and osseointegration of porous titanium implants in the repair of long bone defects. Sci. Rep. 5, 1-13. doi: 10.1038/ srep 17134 
Jing, D., Yan, Z., Cai, J., Tong, S., Li, X., Guo, Z., et al. (2018). Low-1 level mechanical vibration improves bone microstructure, tissue mechanical properties and porous titanium implant osseointegration by promoting anabolic response in type 1 diabetic rabbits. Bone 106, 11-21. doi: 10.1016/j. bone.2017.10.001

Khosla, S. (2001). Minireview: the OPG/RANKL/RANK system. Endocrinology 142, 5050-5055.

Kim, I. S., Song, Y. M., Lee, B., and Hwang, S. J. (2012). Human mesenchymal stromal cells are mechanosensitive to vibration stimuli. J. Dent. Res. 91, 11351140. doi: $10.1177 / 0022034512465291$

Kolf, C. M., Cho, E., and Tuan, R. S. (2007). Mesenchymal stromal cells. Biology of adult mesenchymal stem cells: regulation of niche, self-renewal and differentiation. Arthrit. Res. Ther. 9:ar2116. doi: 10.1186/ar2116

Komori, T., Yagi, H., Nomura, S., Yamaguchi, A., Sasaki, K., Deguchi, K., et al. (1997). Targeted disruption of Cbfal results in a complete lack of bone formation owing to maturational arrest of osteoblasts. Cell 89, 755-764. doi: 10.1016/S0092-8674(00)80258-80255

Kovtun, A., Bergdolt, S., Wiegner, R., Radermacher, P., Huber-Lang, M., and Ignatius, A. (2016). The crucial role of neutrophil granulocytes in bone fracture healing. Eur. Cells Mater. 32, 152-162. doi: 10.22203/eCM.v03 2a10

Lanyon, L. E. (1993). Osteocytes, strain detection, bone modeling and remodeling. Calcif. Tissue Int. 53:415. doi: 10.1007/BF01673415

Lau, E., Lee, W. D., Li, J., Xiao, A., Davies, J. E., Wu, Q., et al. (2011). Effect of low-magnitude, high-frequency vibration on osteogenic differentiation of rat mesenchymal stromal cells. J. Orthop. Res. 29, 1075-1080. doi: 10.1002/jor. 21334

Lau, R. W. K., Liao, L. R., Yu, F., Teo, T., Chung, R. C. K., and Pang, M. Y. C. (2011). The effects of whole body vibration therapy on bone mineral density and leg muscle strength in older adults: a systematic review and meta-analysis. Clin. Rehabil. 25, 975-988. doi: 10.1177/0269215511405078

Leung, K. S., Shi, H. F., Cheung, W. H., Qin, L., Ng, W. K., Tarn, K. F., et al. (2009). Low-magnitude high-frequency vibration accelerates callus formation, mineralization, and fracture healing in rats. J. Orthop. Res. 27, 458-465. doi: $10.1002 /$ jor. 20753

Li, Y., Liu, G., Yu, J., Li, C., Tan, L., Hao, B., et al. (2018). Effects of continuous or intermittent low-magnitude high-frequency vibration on fracture healing in sheep. Int. Orthop. 42, 939-946. doi: 10.1007/s00264-018-3759-3754

Li, H., Wu, W., He, X., Cao, C., Yu, X., Zeng, Y., et al. (2019). Applying vibration in early postmenopausal osteoporosis promotes osteogenic differentiation of bone marrow-derived mesenchymal stem cells and suppresses postmenopausal osteoporosis progression. Biosci. Rep. 39:BSR20191011. doi: 10.1042/BSR20191011

Lian, J. B., and Stein, G. S. (1995). Development of the osteoblast phenotype: molecular mechanisms mediating osteoblast growth and differentiation. Iowa Orthop. J. 15, 118-140.

Liang, Y. Q., Qi, M. C., Xu, J., Xu, J., Liu, H. W., Dong, W., et al. (2014). Lowmagnitude high-frequency loading, by whole-body vibration, accelerates early implant osseointegration in ovariectomized rats. Mol. Med. Rep. 10, 2835-2842. doi: 10.3892/mmr.2014.2597

Lu, Y., Zhao, Q., Liu, Y., Zhang, L., Li, D., Zhu, Z., et al. (2018). Vibration loading promotes osteogenic differentiation of bone marrow-derived mesenchymal stem cells via p38 MAPK signaling pathway. J. Biomech. 71, 67-75. doi: 10.1016/ j.jbiomech.2018.01.039

Marycz, K., Lewandowski, D., Tomaszewski, K. A., Henry, B. M., Golec, E. B., and Marędziak, M. (2016). Low-frequency, low-magnitude vibrations (LFLM) enhances chondrogenic differentiation potential of human adipose derived mesenchymal stromal stem cells (hASCs). PeerJ 2016:eerj.1637.

Mehta, S. (2015). Hydrogel Encapsulation of Cells Mimics the Whole Body Response to LMHF Vibrations. Ph.D thesis, Rutgers University Libraries, New Brunswick, NJ.

Miclau, K. R., Brazina, S. A., Bahney, C. S., Hankenson, K. D., Hunt, T. K., Marcucio, R. S., et al. (2017). Stimulating fracture healing in Ischemic environments: does oxygen direct stem cell fate during fracture healing? Front. Cell Dev. Biol. 5:45. doi: 10.3389/fcell.2017.00045

$\mathrm{Mu}, \mathrm{D}$., Yu, J., Lin, J., Li, C., Hao, B., Gu, F., et al. (2019). Intermittent vibrations accelerate fracture healing in sheep. Acta Cir. Bras. 34:e201900702. doi: 10.1590/ s0102-865020190070000002
Neidlinger-Wilke, C., Wilke, H.-J., and Claes, L. (1994). Cyclic stretching of human osteoblasts affects proliferation and metabolism: a new experimental method and its application. J. Orthop. Res. 12, 70-78. doi: 10.1002/jor.1100120109

Nikolaou, V. S., Efstathopoulos, N., Kontakis, G., Kanakaris, N. K., and Giannoudis, P. V. (2009). The influence of osteoporosis in femoral fracture healing time. Injury 40, 663-668. doi: 10.1016/j.injury.2008.10.035

Ogawa, T., Possemiers, T., Zhang, X., Naert, I., Chaudhari, A., Sasaki, K., et al. (2011a). Influence of whole-body vibration time on peri-implant bone healing: a histomorphometrical animal study. J. Clin. Periodontol. 38, 180-185. doi: 10.1111/j.1600-051X.2010.01637.x

Ogawa, T., Zhang, X., Naert, I., Vermaelen, P., Deroose, C. M., Sasaki, K., et al. (2011b). The effect of whole-body vibration on peri-implant bone healing in rats. Clin. Oral Implants Res. 22, 302-307. doi: 10.1111/j.1600-0501.2010. 02020.x

Ogawa, T., Vandamme, K., Zhang, X., Naert, I., Possemiers, T., Chaudhari, A., et al. (2014). Stimulation of titanium implant osseointegration through highfrequency vibration loading is enhanced when applied at high acceleration. Calcif. Tissue Int. 95, 467-475. doi: 10.1007/s00223-014-9896-x

Ota, T., Chiba, M., and Hayashi, H. (2016). Vibrational stimulation induces osteoblast differentiation and the upregulation of osteogenic gene expression in vitro. Cytotechnology 68, 2287-2299. doi: 10.1007/s10616-016-0023-x

Owen, T. A., Aronow, M., Shalhoub, V., Barone, L. M., Wilming, L., Tassinari, M. S., et al. (1990). Progressive development of the rat osteoblast phenotype in vitro: reciprocal relationships in expression of genes associated with osteoblast proliferation and differentiation during formation of the bone extracellular matrix. J. Cell. Physiol. 143, 420-430. doi: 10.1002/jcp.1041430304

Pauwels, F. (1960). Eine neue theorie über den Einfluß mechanischer reize auf die differenzierung der stützgewebe - zehnter beitrag zur funktionellen anatomie und kausalen morphologie des stützapparates. Z. Anat. Entwicklungsgesch. 121, 478-515. doi: 10.1007/BF00523401

Perren, S. M. (1979). Physical and biological aspects of fracture healing with special reference to internal fixation. Clin. Orthop. Relat. Res. 138, 175-196.

Pittenger, M. F., Mackay, A. M., Beck, S. C., Jaiswal, R. K., Douglas, R., Mosca, J. D., et al. (1999). Multilineage potential of adult human mesenchymal stem cells. Science 284, 143-147. doi: 10.1126/science.284.5411.143

Pongkitwitoon, S., Uzer, G., Rubin, J., and Judex, S. (2016). Cytoskeletal configuration modulates mechanically induced changes in mesenchymal stem cell osteogenesis, morphology, and stiffness. Sci. Rep. 6, 1-12. doi: 10.1038/ srep34791

Pravitharangul, A., Suttapreyasri, S., and Leethanakul, C. (2018). Iliac and mandible osteoblasts exhibit varied responses to LMHF vibration. Cell Biol. Int. 42, 1349-1357. doi: 10.1002/cbin.11019

Quarles, L. D., Yohay, D. A., Lever, L. W., Caton, R., and Wenstrup, R. J. (1992). Distinct proliferative and differentiated stages of murine MC3T3-E1 cells in culture: an in vitro model of osteoblast development. J. Bone Miner. Res. 7, 683-692. doi: 10.1002/jbmr.5650070613

Rastegar, F., Shenaq, D., Huang, J., Zhang, W., Zhang, B.-Q., He, B.-C., et al. (2010). Mesenchymal stem cells: molecular characteristics and clinical applications searched and summarized relevant literature. World J Stem Cells 2, 67-80. doi: $10.4252 /$ wjsc.v2.i4.67

Rosenberg, N., Levy, M., and Francis, M. (2002). Experimental model for stimulation of cultured human osteoblast-like cells by high frequency vibration. Cytotechnology 39, 125-130. doi: 10.1023/A:1023925230651

Rubin, C. T., Recker, R., Cullen, D., Ryaby, J., McCabe, J., and McLeod, K. (2004). Prevention of postmenopausal bone loss by a low-magnitude, high-frequency mechanical stimuli: a clinical trial assessing compliance, efficacy, and safety. J. Bone Miner. Res. 19, 343-351. doi: 10.1359/JBMR.0301251

Ruppert, D. S., Harrysson, O. L. A., Marcellin-Little, D. J., Dahners, L. E., and Weinhold, P. S. (2018). Improved osseointegration with as-built electron beam melted textured implants and improved peri-implant bone volume with whole body vibration. Med. Eng. Phys. 58, 64-71. doi: 10.1016/j.medengphy.2018.05. 003

Sakamoto, M., Fukunaga, T., Sasaki, K., Seiryu, M., Yoshizawa, M., Takeshita, N., et al. (2019). Vibration enhances osteoclastogenesis by inducing RANKL expression via NF- $\mathrm{KB}$ signaling in osteocytes. Bone 123, 56-66. doi: 10.1016/j. bone.2019.03.024

Shi, H. F., Cheung, W. H., Qin, L., Leung, A. H. C., and Leung, K. S. (2010). Lowmagnitude high-frequency vibration treatment augments fracture healing in 
ovariectomy-induced osteoporotic bone. Bone 46, 1299-1305. doi: 10.1016/j. bone.2009.11.028

Shibamoto, A., Ogawa, T., Duyck, J., Vandamme, K., Naert, I., and Sasaki, K. (2018). Effect of high-frequency loading and parathyroid hormone administration on peri-implant bone healing and osseointegration. Int. J. Oral Sci. 10:6. doi: 10.1038/s41368-018-0009-y

Simonet, W. S., Lacey, D. L., Dunstan, C. R., Kelley, M., Chang, M. S., Lüthy, R., et al. (1997). Osteoprotegerin: a novel secreted protein involved in the regulation of bone density. Cell 89, 309-319. doi: 10.1016/S0092-8674(00) 80209-80203

Slatkovska, L., Alibhai, S. M. H., Beyene, J., and Cheung, A. M. (2010). Effect of whole-body vibration on BMD: a systematic review and meta-analysis. Osteoporos. Int. 21, 1969-1980. doi: 10.1007/s00198-010-1228- Z

Tan, L., Shicai, Y., Guozhao, L., Bin, Z., Chao, L., Baohui, H., et al. (2016). Low magnitude continuous and intermittent mechanical vibration effects on nanoscale topography and mechanical properties of bone fracture healing. J. Biomater. Tissue Eng. 6, 810-817. doi: 10.1166/jbt.2016.1503

Tan, L., Li, Y.-H., Zhao, B., Li, Y., and Zhu, D. (2017). Intermittent Low-Magnitude High-Frequency Vibration Enhances Biological and Radiological Parameters During Fracture Healing in Sheep. Available online at: www.ijcep.com/ (accessed May 24, 2020).

Tezval, M., Biblis, M., Sehmisch, S., Schmelz, U., Kolios, L., Rack, T., et al. (2011). Improvement of femoral bone quality after low-magnitude, high-frequency mechanical stimulation in the ovariectomized rat as an osteopenia model. Calcif. Tissue Int. 88, 33-40. doi: 10.1007/s00223-010-9423-9427

Thompson, W. R., Uzer, G., Brobst, K. E., Xie, Z., Sen, B., Yen, S. S., et al. (2015). Osteocyte specific responses to soluble and mechanical stimuli in a stem cell derived culture model. Sci. Rep. 5:11049. doi: 10.1038/srep11049

Uzer, G., Pongkitwitoon, S., Ete Chan, M., and Judex, S. (2013). Vibration induced osteogenic commitment of mesenchymal stem cells is enhanced by cytoskeletal remodeling but not fluid shear. J. Biomech. 46, 2296-2302. doi: 10.1016/j. jbiomech.2013.06.008

Uzer, G., Pongkitwitoon, S., Ian, C., Thompson, W. R., Rubin, J., Chan, M. E., et al. (2014). Gap junctional communication in osteocytes is amplified by low intensity vibrations in vitro. PLoS One 9:e90840. doi: 10.1371/journal.pone. 0090840

Uzer, G., Thompson, W. R., Sen, B., Xie, Z., Yen, S. S., Miller, S., et al. (2015). Cell mechanosensitivity to extremely low magnitude signals is enabled by a LINCed nucleus HHS public access. Stem Cells 33, 2063-2076. doi: 10.1002/stem.2004

Ward, K., Alsop, C., Caulton, J., Rubin, C., Adams, J., and Mughal, Z. (2004). Low magnitude mechanical loading is osteogenic in children with disabling conditions. J. Bone Miner. Res. 19, 360-369. doi: 10.1359/JBMR.040129

Wehrle, E., Liedert, A., Heilmann, A., Wehner, T., Bindl, R., Fischer, L., et al. (2015). The impact of low-magnitude high-frequency vibration on Fracture healing is profoundly influenced by the oestrogen status in mice. DMM Dis. Model. Mech. 8, 93-104. doi: 10.1242/dmm.018622
Wehrle, E., Wehner, T., Heilmann, A., Bindl, R., Claes, L., Jakob, F., et al. (2014). Distinct frequency dependent effects of whole-body vibration on non-fractured bone and fracture healing in mice. J. Orthop. Res. 32, 1006-1013. doi: 10.1002/ jor. 22629

Wenger, K. H., Freeman, J. D., Fulzele, S., Immel, D. M., Powell, B. D., Molitor, P., et al. (2010). Effect of whole-body vibration on bone properties in aging mice. Bone 47, 746-755. doi: 10.1016/j.bone.2010.07.014

Wu, S. H., Zhong, Z. M., and Chen, J. T. (2012). Low-magnitude high-frequency vibration inhibits RANKL-induced osteoclast differentiation of RAW264.7 cells. Int. J. Med. Sci. 9, 801-807. doi: 10.7150/ijms.4838

Xie, L., Jacobson, J. M., Choi, E. S., Busa, B., Donahue, L. R., Miller, L. M., et al. (2006). Low-level mechanical vibrations can influence bone resorption and bone formation in the growing skeleton. Bone 39, 1059-1066. doi: 10.1016/j. bone.2006.05.012

Zhang, Y., Böse, T., Unger, R. E., Jansen, J. A., Kirkpatrick, C. J., and van den Beucken, J. J. J. P. (2017). Macrophage type modulates osteogenic differentiation of adipose tissue MSCs. Cell Tissue Res. 369, 273-286. doi: 10.1007/s00441-0172598-2598

Zhang, N., Chim, Y. N., Wang, J., Wong, R. M. Y., Chow, S. K. H., Cheung, W. H., et al. (2020). Impaired fracture healing in sarco-osteoporotic mice can be rescued by vibration treatment through myostatin suppression. J. Orthop. Res. 38, 277-287. doi: 10.1002/jor.24477

Zhou, Y., Guan, X., Liu, T., Wang, X., Yu, M., Yang, G., et al. (2015). Whole body vibration improves Osseointegration by up-regulating osteoblastic activity but down-regulating osteoblast-mediated Osteoclastogenesis via ERK1/2 pathway. Bone 71, 17-24. doi: 10.1016/j.bone.2014. 09.026

Zhou, Y., Guan, X., Zhu, Z., Gao, S., Zhang, C., Li, C., et al. (2011). Osteogenic differentiation of bone marrow-derived mesenchymal stromal cells on bonederived scaffolds: effect of microvibration and role of ERK1/2 activation. Eur. Cells Mater. 22, 12-25. doi: 10.22203/eCM.v022a02

Ziambaras, K., Lecanda, F., Steinberg, T. H., and Civitelli, R. (1998). Cyclic stretch enhances gap junctional communication between osteoblastic cells. J. Bone Miner. Res. 13, 218-228. doi: 10.1359/jbmr.1998.13.2.218

Conflict of Interest: The authors declare that the research was conducted in the absence of any commercial or financial relationships that could be construed as a potential conflict of interest.

Copyright (c) 2020 Steppe, Liedert, Ignatius and Haffner-Luntzer. This is an openaccess article distributed under the terms of the Creative Commons Attribution License (CC BY). The use, distribution or reproduction in other forums is permitted, provided the original author(s) and the copyright owner(s) are credited and that the original publication in this journal is cited, in accordance with accepted academic practice. No use, distribution or reproduction is permitted which does not comply with these terms. 